the sudden rise to $100 \cdot 2^{\circ}$, to as suddenly drop to normal. The catheter was removed altogether on the morning of the sixth day, when the urine was drawn off until the fourteenth day. For some little time she experienced vesical irritation, but this passed away. Her legs, which were kept well bent by having two pillows tied behind the knees, were allowed down on the fourteenth day; now considered gradually convalescing. The patient was allowed up on the twentyfifth day after the operation. She ate well; all stimulants discontinued since the fifteenth day, She looked well. On examining the parts the vagina was found quite healthy and smooth; no indication of any growth; the finger passed into a cul-de-sac, where a transverse slit was felt, being the position of the os, with no special contraction of parts; no pain; no discharge; little bladder irritation, only after micturition; bowels regular; appetite good; thoroughly convalescent.

Discharged from hospital on Nov. 4th, forty-second day after operation. She was anxious to leave several days before $I$ gave consent, as I wished my colleagues to examine her.

I cannot omit to mention the great skill and attention bestowed on this patient by Mr. Briscoe, our house-surgeon, whose lot it was to have the care of the two vaginal hysterectomy cases operated on by Dr. Wm. A. Duncan, and the second brought to a successful issue; I cannot too highly praise the nurses who were in charge. To my colleagues and to Mr. Jessett I tender my thanks for their kind assistance at the operation.

In the present state of abdominal surgery it is difficult to say what are its limits; but it is one thing to determine what is possible and another what is advisable. To the German surgeons belong whatever credit is due for the modern revival of vaginal hysterectomy ; their results were known to be much ahead of those obtained in this country, where they had been bad; their mortality may be put down at 28 to 32 per cent. We may, it is hoped, regard the vaginal extirpation of the cancerous uterus as an eminently rational one in an affection so surely fatal when left to itself as carcinoma, claiming for it no more nor less than what is to be expected from excision of the tongue or rectum, or amputation of the breast. Abdominal hysterectomy is a very fatal procedure; its mortality has been 68 per cent. (Hegar and Kaltenbach), and the death-rate does not appear to be diminishing by increased experience ; vaginal hysterectomy, on the other hand, yields more promising results, and is progressively improving in its death-rate, and should be persevered in with the hope that it will ultimately become a far more successful measure than it has proved to be up to the present date.

As no closure of the peritoneum was undertaken in my case, we must presume that a limiting membrane is thrown out by the plastic peritonitis excited by the operation. The bladder falling back on to the posterior wall of the vagina and rectum closes in the depending aperture formed by the removal of the uterus and its right ovary, which was cystic and its Fallopian tube. In the case of cancer of the cervix ateri the frequency of the disease makes the question of treatment one of ever-persistent importance; the disease is manifestly localised, and not general in many cases, and a hope of cure is not to be denied. Practice seems to have separated itself into two widely divergent lines. On the one hand, to treat the disease by extirpation of the whole organ, or by the supravaginal excision; and, on the other hand, to remove the disease only in those cases in which a protuberant mass presents itself-namely, the partial operation on the cervix, with the addition of the application of chloride of zinc, potassa fusa, bromine, or the actual cautery. This latter practice implies the abandonment of " some" women whom a more hopeful view might have helped to cure, and very many of whom might have been relieved, not reckoning of course the immediate risks of the operation. Herein lie the vital importance and necessity of seeing and operating upon cases in their initial stages, if women are to be relieved from misery and suffering and death. Of the final results of the vaginal operation our information is scanty and requires a more rigid following up of each case. Freedom from recurrence may be placed at an average of fourteen months. The prognosis will no doubt improve, especially if the operation be performed early and radieally; even if a recurrence take place, the patient suffers little towards the end of her life comparatively, for the disease generally does not recur on the cicatrix in the vaginal formix. It spreads upwards on to the pelvic cellular tissue, and the patient is saved from hæmorrhage and ulceration.

N.B.-The specimen was shown on Wednesday evening, 14th inst., at the Obstetrical Society of London.

Manchester-square, $\mathrm{W}$

NOTE ON THE

\section{ACTION OF PARALDEHYDE, THE NEW HYPNOTIC.}

By S. A. K. STRAHAN, M.D.,

ASSISTANT MEDICAL OFFICER, COUNTY ASFLUM, NORTHAMPTON.

Paratidehyde, which was first used as a therapeutic agent by Dr. Cervello, of Palermo, some eighteen months ago, hasnot received in this country the attention it deserves. As a sleep-producer it stands in the same rank with chloral; while in anything like moderate doses it approaches in safety that safest of all sedatives, bromide of potassium. I have employed it over 150 times in about twenty-five cases, and have found but two patients who did not respond to medium doses of the drug. One of these was suffering from acute mania, and the other from severe facial neuralgia. I have given it in mania, acute and chronic, melancholia, dementia, the various stages of general paralysis, during those periods of restlessness and sleeplessness so often met with in idiots and imbeciles, and in simple insomnia, and have found it almost invariably a certain somniferent. Paraldehyde acts more quickly than chloral. When a dose is taken a feeling of warmth, a kind of grateful glow, is experienced, and the patient is often asleep within ten or fifteen minutes. When it does not produce sleep it does not excite, but rather tends to soothe and calm an excited or depressed patient.

The sleep induced by paraldehyde is, I think, a nearer approach to natural sleep than that obtained by the administration of any other drug. It is light, apparently dreamless, and certainly refreshing; the patient can at any time be awakened by a loud word or a gentle shake, and when so aroused does not display any alarm or confusion of ideas, and if left alone at once falls to sleep again. During this sleep the breathing is somewhat slower and deeper than in the waking hours, while the pulse becomes slightly less rapid, and possibly stronger. The temperature (surface) is not changed, the flow of urine is increased, and the skin is not affected. No headache or other unpleasant symptom is experienced on waking, and the appetite is not injured even by the daily exhibition of the drug for considerable periodsin one of my cases for over three weeks.

The dose is from thirty to ninety minims, but more than sixty drops is seldom required to induce sleep; and this, or even a smaller dose repeated within an hour, is much more effective than a single large dose. The paraldehyde is best given as its first adminstrators recommend-that is, with a bitter tincture in sweetened water. It has a pungent taste, but a drachm when combined with fifteen drops of tincture of orange and an ounce or more of water sweetened with syrup makes a not unpleasant draught, never in my experience causing nausea or vomiting. The drug is given off principally or wholly by the lungs, and may easily be detected in the breath for ten, twelve, or more hours.

To sum up now all that can be said in favour of this drug. It is an equally sure hypnotic with chloral, it does not in any case produce excitement before sleep, it leaves no headache nor other unpleasant symptom on awaking, and it does not affect the appetite. These are all matters of not slight importance, but there is one advantage which this drug possesses over chloral which at once gives it a place among our most useful hypnotics, and that is the absence of any depressing or paralysing action on the heart. This absence of action upon the cardiac centre permits of its being given with perfect safety to general paralytics and others to whom chloral would only be given with the greatest caution and with constant anxiety as to the result of even small doses. The new drug may not take the place of chloral in everyday prescribing, but it must supplant it in those, unhappily numerous, cases in which the action of the sedative upon the heart is to be feared and yet where sleep is often so much to be desired.

Paraldehyde may yet be found to be possessed of other 
useful properties. I have given it in a few cases of facial neuralgia. In two cases it acted like a charm, while in all the others its effect was nil. I have also found it useful in a case of "nervous headache."

Northampton.

\section{dittirror}

\section{HOSPITAL PRACTICE BRITISH AND FOREIGN.}

Nulla autem est alia pro certo noscendi via, nisi quamplurimas at morborum et dissectionum historias, tum aliorum tum proprias collecto habere, et inter se comparare.-Morgagni De Sed. et Caus. Morb. lib. iv. Proœmium.

\section{KING'S COLLEGE HOSPITAL.}

SIMPLE DEPRESSED FRACTURE OF SKULL; TREPHINING; RECOVERY.

(Under the care of Mr. WILLIAM Rose.)

Fon the following notes we are indebted to Mr. Penny, house-surgeon. (This case was brought under the notice of the Fellows of the Medical Society, Jan. 26th, 1885.)

H. C- aged thirty-three, was brought to the hospital at 12.15 A.M. on Nor. 25 th, having fallen down a flight of stone stairs. He was insensible; respiration stertorous; pulse very feeble; pupils equally dilated and reacting to light; he had passed urine and fæces in his trousers; there was no evidence of his being in liquor. There was a depressed fracture of the skull, which could clearly be felt, although the scalp was not wounded, one inch and a quarter to the left of the median line, and close to the left occipitoparietal suture. When put to bed, he lay perfectly motionless for about three-quarters of an hour, after which he began to moan and move his limbs slightly, commencing with his arms, his right leg being the last to move. There was no bleeding from the ears, nose, or mouth. A large hæmatoma rapidly. developed under the scalp at the seat of injury. $\mathrm{He}$ was seen at 1.30 A.M. by Mr. William Rose, who decided to cut down upon the fracture, the patient being still unconscious and the history of the accident and the abruptly defined nature of the fracture pointing probably to splintering of the inner table. The patient was placed under chloroform in the theatre, and under the carbolic spray an incision about two and a half inches long was made over the most depressed part, and another at right angles, to give additional room to work the trephine, which was then applied close to the edge of the sound bone. The pericranium was carefully detached and turned aside. There appeared to be one long fissured fracture running antero-posteriorly, with two others radiating off at right angles, comprising between them the portion of depressed bone, which, as far as could be ascertained, might have measured a square inch. The diameter of the trephine used was three-quarters of an inch. On removing the semicircular portion of bone, the elevator was inserted, and the bone, which was depressed about the thickness of the skull, was elevated. Two small spicula of the inner table were found loose and removed. As far as could be seen, the dura mater was intact. The wound was then carefully examined for other loose fragments, and none being found, the bleeding points were secured by catgut ligature, the wound united with carbolised silk sutures, a small drainagetube inserted through the thickness of the scalp only, and dressed with protective and carbolised gauze. The patient vomited freely during the operation, and afterwards became very restless. An ice-bag was applied to the head outside the dressing, and hot-water bottles to the feet. At 3.50 A.M. however, he was sleeping quietly. Respiration 20; pulse 96 ; temperature $99^{\circ}$; feet warm. At 10.30 A.M. he could be roused to answer questions, but occasionally gave wrong answers. He kept fairly quiet if not touched, but objected to be moved, especially to having a catheter passed; twentyfour ounces of urine were drawn off. 2.30 P.M. : Complained of frontal headache; no pain at back of head; wound dressed; a good deal of bloody discharge; wound looks well. Temperature $99^{\circ}$; pulse 120. Five grains of calomel were ordered. 6 P.M. : Gave so much trouble, and excited himself so much when urine was drawn off, that chloroform was administered for the purpose.

Nov. $26 \mathrm{~h},-$ Very restless at night; says the pain is not at back, but in the front of head. Takes about forty ounces of fluid in twenty-four hours. Evening temperature $99 \cdot 4^{\circ}$; pulse 108. Ordered five grains of calomel and fifteen grains of powdered jalap. He is much more sensible and intelligent, though he sometimes attempts to pull off his dressings and gives wrong answers to questions.

27 th.-Bowels opened freely, and passed urine for the first time since the operation. Expresses himself as much better and in less pain. Wound dressed; very slight discharge; drainage-tube left out. In the evening complained of pain over the right parietal bone; very thirsty, and has taken five pints of fluid in twenty-four hours. Still restless if disturbed.

28th.-Slept well; not so restless, and is quite sensible; answers questions well. In the evening the pain over the right parietal bone was worse. Three pints and a half of fluid taken in twenty-four hours. Temperature $982^{\circ}$; pulse 68. Ordered five grains of calomel and fifteen grains of powdered jalap.

29th.-Very restless, with severe pain all over back of the head; cannot bear the least noise, movement, or bright light. Pupils still equal and react to light. Isolated and room darkened.

30th.-Wound dressed; healed, except track of drainagetube. Stitches removed. Ordered two grains of calome? every six hours. Much easier after dressing. Temperature $97 \cdot 2^{\circ}$; pulse 68 . Feels hungry. Allowed a little toast and tea.

Dec. 2nd.--Wound dressed; still a small speck not healed. Can hear very well with both ears. Has rather a vague idea of time (in a darkened room). Can remember nothing about the accident. Temperature $98^{\circ} 2^{\circ}$; pulse 70 .

4th.-Slept well. Much more cheerful and pain in the head almost gone. Noise irritates him much less. Allowed a little fish, which he enjoyed.

5th.-Noise does not irritate him. No pain in head. Asked to see a newspaper.

6th.- Taken back to general ward. Enjoys the company. 11th.-Wound quite healed. Some tenderness over scar.

13th.-Allowed to read, which causes no headache. No tenderness. Wishes to go home.

15th.-Discharged on the twentieth day from admission, Total number of dressings, six.

\section{HOSPITAL FOR WOMEN, NOTTINGHAM.}

CASES UNDER THE CARE OF DR. GEORGE ELDER.

THE first and second are cases of obstruction of the lower bowel, in the one case by syphilitic stricture, in the other by pressure around the rectum, diminishing its calibre. Both patients did well after the operation of colotomy, and each enjoys a prospect of a greatly prolonged life. In the third case Dr. Elder successfully removed part of the scapula for sarcomatous tumour growing from the bone. The operation, as is usual, was protracted, and there was considerable hæmorrhage. Two months later there was no evidence of recurrence.

CASE 1.- Syphilitic Stricture and Ulceration of the Rectum; Colotomy; Recovery. - Mrs. R_- aged fifty years, was admitted into hospital on July 10th, 1883. In addition to a history of syphilis acquired some years ago and neglected, there were evidences of it in the legs in the shape of the remains of rupial ulcerations and tibial nodes. No trouble in defecating was noticed till three years before admission, and this has increasingly become worse; until now the habitual use of aperients is required; but on account of the pain it entails, the patient dreads a movement of the bowels. Of late there has been an almost constant tenesmus and oozing of liquid fæces and muco-pus, and the excrement is formless. As a consequence of the exhausting nature of the discharges, the pain and the interference with nutrition, patient's general health has become very much impaired. On examination it was found that in addition to some degree of ulceration there existed a tight cicatricial contraction of the lumen of the bowel an inch above the anus. Left colotomy (loin) was performed on July 11th. There was no difficulty about the operation, but the progress towards recovery was retarded, first, by suppuration in the track of two of the sutures (carbolised silk); secondly, by formation of pus amongst the connective tissue at the sides of the bowel. Yet, notwithstanding these drawbacks, the patient went out on August 3rd much relieved and benefited by the operation. For some months she appeared amongst the out-patients, seemingly in perfect 